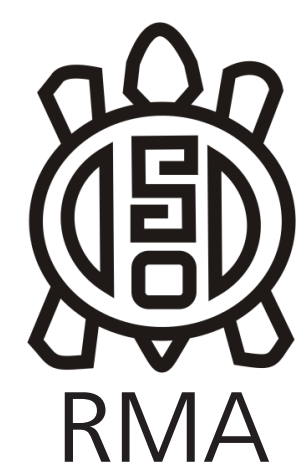

Antropología Social

\title{
Las narrativas de madres y bailarinas en el circuito profesional del tango danza en Buenos Aires
}

\author{
The narratives of mothers and dancers in the professional tango dance \\ circuit in Buenos Aires \\ Juliana Verdenelli*
}

\begin{abstract}
*Instituto de Investigaciones en Humanidades y Ciencias Sociales de la Universidad Nacional de La Plata/ Escuela Interdisciplinaria de Altos Estudios Sociales de la Universidad Nacional de San Martín. E-mail: juliverdenelli@gmail.com
\end{abstract}

\begin{abstract}
Resumen
Este artículo indaga acerca de la política narrativa (Ortner, 2006) que participa en la construcción de agencia de las bailarinas de tango que desean conciliar su profesión con su maternidad. A partir del análisis de las composiciones musicales de tango de las primeras dos décadas del siglo veinte y de la exploración del registro fílmico Un tango más (2015), el estudio se pregunta por los modos en que estas historias se nutren de la política cultural de la diferencia y la desigualdad de género y por cómo participan en la organización experiencias y la construcción de representaciones, sentidos e imaginarios sobre la madre y la bailarina en el circuito profesional del tango danza en Buenos Aires. En base a los datos relevados durante un trabajo de campo etnográfico realizado entre 2013 y 2020 -en el que se siguió a bailarinas profesionales que también son madres-, se concluye que las narrativas asociadas a las figuras de la madre y la milonguita del tango continúan operando en las subjetividades de muchas artistas y entran en tensión de diferentes maneras -y en diversos grados- en sus prácticas cotidianas. Estas tensiones generan, por momentos, sentimientos de profunda incompatibilidad entre la maternidad y el tango.
\end{abstract}

Palabras clave: Maternidad; Tango danza; Agencia; Narrativas; Género.

\begin{abstract}
This article addresses the narrative politics (Ortner, 2006) that take part in the construction of agency of the tango dancers who want to conciliate their profession with their maternity. From the analysis of the musical tango compositions of the first two decades of the twentieth century and the exploration of the film Un tango más (2015), the study inquiries the ways in which these stories are nourished by the cultural politics of the difference and gender inequality. Also, how they participate in the organization of experiences and the construction of cultural representations, senses and imaginary about mothers and dancers in the professional tango dance circuit in Buenos Aires. Based on the information collected during an ethnographic fieldwork made between 2013 and 2020 - in which professional dancers who are also mothers were followed-, one concludes that the narratives associated with the figures of the mother and the tango's milonguita keep on operating in the subjectivities of many artists and generating tensions in different ways - and in diverse grades - in their daily practices. These tensions also generate, at times, feelings of deep incompatibility between the maternity and the tango.
\end{abstract}

Key Words: Maternity; Tango dance; Agency; Narratives; Gender.

\section{Introducción}

En este artículo se indaga acerca de la política narrativa (Ortner, 2006) que participa en la construcción de agencia de las bailarinas de tango que desean conciliar su profesión con su maternidad.

En una primera instancia, se analiza las figuras de la milonguita y la madre en las letras de las composiciones musicales de tango de las primeras dos décadas del siglo veinte, a fin de establecer cómo se distribuye agencia en estas historias. Luego, se explora un registro fílmico desde el punto de vista de las políticas narrativas: la película Un tango más (2015).

En línea con la propuesta de Sherry Ortner, estos materiales se analizan como "formaciones culturales que construyen y distribuyen agencia de maneras específicas 
como parte de la política cultural de creación apropiada de individuos con género en ese tiempo y lugar particular" (2006: 164).

Desde esta perspectiva, el estudio se pregunta por los modos en que estas historias se nutren de la política cultural de la diferencia y la desigualdad de género y por cómo participan en la organización experiencias y en la construcción de representaciones, sentidos e imaginarios sobre la madre y la bailarina en el circuito profesional del tango bailado en Buenos Aires.

Es importante mencionar que este trabajo no busca establecer una genealogía sobre la madre y la bailarina en el tango, sino observar los diálogos, las rupturas y las continuidades que se establecen entre: 1) las narrativas de las letras de tango de principios de siglo XX (momento en el que fijan su atención múltiples investigaciones sociales para estudiar el vínculo del baile social con el proceso de normalización de la sexualidad femenina en Argentina); 2) la historia de María Nieves Rego (una figura clave para pensar el proceso de profesionalización del tango danza); y 3) las experiencias situadas de las mujeres que formaron parte de mi investigación doctoral. Para eso, en los últimos aparados se recuperan los relatos de algunas madres y bailarinas profesionales de tango en base a un trabajo de campo etnográfico realizado entre 2013 y 2020.

En el marco de un estudio sobre los balances entre la profesión y la maternidad de bailarinas de tango y bailarinas de contemporáneo en la ciudad de Buenos Aires (Verdenelli, 2020), durante este período se "siguió" etnográficamente a un grupo de bailarinas madres -todas ellas heterosexuales, blancas, jóvenes y de mediana edad, cisgénero y de sectores medios urbanos- en sus actividades cotidianas, con el objetivo de describir y analizar etnográficamente sus experiencias situadas de maternidad en relación con sus trayectorias artísticas.

A partir de la categoría propuesta por Mariana Sáez (2017) de práctica corporal artística, se consideró que la cuestión de lo corporal en vinculación con lo artístico convertía a la danza en un terreno privilegiado para indagar sobre los conflictos o las disputas que enfrentan las mujeres que desean conciliar sus maternidades con sus carreras artísticas. En este sentido, se optó por hacer foco en las experiencias de maternidad que resultan de una transformación corporal temporal asociada a la gestación, que es exteriormente perceptible y socialmente significada, para indagar cómo los cambios fisiológicos que tienen lugar durante la gestación, el parto y el puerperio se impregnan de sentido y adquieren un carácter de cambio social (Imaz, 2010).

Si bien la observación atendió al modo en que se entraman lo corporal con lo cultural, lo cinético, lo afectivo y lo moral en las experiencias situadas de estas mujeres, también indagó la compleja relación que existe entre el deseo y la construcción del ser -madre y bailarinaa la luz de los debates feministas de los últimos años.

Se comparten aquí algunos resultados obtenidos en este estudio antropológico. Específicamente, aquellos que abordan los repertorios culturales, las representaciones sociales y los imaginarios que se activan para dificultar el balance entre la profesión y la maternidad de las bailarinas de tango e intervienen en sus horizontes de posibilidad respecto a la profesión. Se parte, para eso, de una definición de agencia que no es sinónimo de resistencia (Ortner, 2006; Mahmood, 2008) y se entiende que una de sus dimensiones más elementales es la capacidad de llevar adelante proyectos y deseos personales, que son constituidos culturalmente y atravesados por múltiples desigualdades y relaciones de poder.

\section{La madre y la milonguita}

La madre y la milonguita fueron dos figuras femeninas muy relevantes en las composiciones musicales de las primeras dos décadas del siglo XX. Las letras de estos tangos las presentan como dos arquetipos contrapuestos, que marcan un límite claro y definido entre lo moralmente correcto y lo moralmente incorrecto desde una mirada masculina, ya que todas las letras eran escritas por hombres.

Por un lado, la milonguita encarna a una mujer joven, soltera y perteneciente a sectores populares urbanos que abandona el barrio, el conventillo y la vida doméstica para sumergirse en el mundo de la noche, el baile del tango y los cabarets del centro porteño. La milonguita es "muy sensual, egoísta y muy segura, con una elevada autoestima que emana de su belleza y elegancia. Se escapa del barrio, probablemente de la pobreza y de un futuro como ama de casa, y va al centro de Buenos Aires" (Archetti, 2003: 208).

Perdida moralmente por los sueños de ascenso social rápido (Cosse, 2010) y seducida por una vida llena de emoción, bailes nocturnos, lujos y placeres (Archetti, 2003), la milonguita "cae", "rueda" o se convierte en "flor de fango", obteniendo a cambio de falsos amores o "amores mentidos" regalos, ropas costosas o champagne. En estas historias "suele aparecer una tercera etapa, generalmente asociada a la vejez o al retiro del cabaret, en la que esos personajes femeninos se ven condenados a la soledad, la enfermedad, la pobreza y la tristeza" (Carozzi, 2014: 110).

Partiendo de los aportes de Sherry Ortner, se indaga de qué modo la presencia o ausencia de agencia en estas composiciones musicales se expresa, principalmente, mediante el lenguaje de la actividad y la pasividad: "la actividad se relaciona con la prosecución de "proyectos"; la pasividad tiene que ver no solo con abstenerse de perseguirlos sino, en cierta forma, con abstenerse, 
incluso, del deseo de perseguirlos" (Ortner, 2006: 162).

Las milonguitas son mujeres sumamente agentivas y activas. Tienen sueños, deseos, proyectos y planes para sus vidas que, por supuesto, siempre terminan mal. Los castigos que reciben, a su vez, parecen justificados en el plano moral. Entro otros tangos sobre milonguitas, pueden mencionarse los siguientes: Flor de Fango (1917); Margot (1919); Mano a mano (1920); Zorro gris (1920); El motivo (1920); Ivette (1920); Milonguita (1920); Pompas de jabón (1925); Che Papusa, oi (1927); Muñeca brava (1928); Milonguera (1929); Mano Cruel (1929) y ¿Sos vos? (1930) (Lamas y Binda, 1998).

María Julia Carozzi $(2014,2015)$ analiza que las historias de las milonguitas en las letras de tango reproducen la asociación entre baile y prostitución, que aparece por primera vez en los poetas de vanguardia en 1910:

si las letras de tangos que hacen referencia a las milonguitas, tal como llegaron hasta nosotros, no hablan explícitamente de intercambio de sexo por dinero, probablemente es porque pasaron por un tamiz inspirado en la moral burguesa antes de ser impresas en partituras y grabadas en discos (Carozzi, 2014: 110).

Según Archetti (2003), las letras de estos tangos constituyen una reacción masculina a las transformaciones en la regulación de la sexualidad femenina'. Desde la perspectiva de los escritores varones -que se toman a sí mismos como ejemplos de virtuosismo y amor romántico-, los tangos describen la vida de las milonguitas como vidas superficiales, vacías y remarcan que la pérdida de la castidad y el usufructo de la sensualidad a través del baile llevan inexorablemente al sufrimiento y a la soledad cuando la juventud desaparece. Las milonguitas suelen ser engañadas y luego abandonadas a su suerte por los bacanes, que son hombres poco confiables, adinerados y manipuladores, que las usan y juegan con ellas.

Para demostrar el sesgo masculino en la mirada sobre la milonguita, Archetti recupera a la única compositora mujer que alcanzó cierta notoriedad durante la década del treinta, María Luisa Carnelli, que escribía usando un pseudónimo de varón: Mario Castro o Luis Castro. Particularmente, en la letra del tango Se va la vida (1929) la sugerencia de Carnelli es radical: "las mujeres deben olvidar el sufrimiento y la virtud, valores impuestos por el hombre y las circunstancias sociales, e ir en busca de la felicidad y la buena vida que ofrece el hombre rico" (Archetti, 2003: 212).

\footnotetext{
1 Archetti (2003) argumenta que los autores de las letras de tango sobre las milonguitas eran varones de mediana edad, solteros, heterosexuales, de clase media baja y descendientes de inmigrantes europeos, que se inspiraban en las mujeres jóvenes que conocían en los lugares públicos de entretenimiento ubicados en el centro de Buenos Aires.
}

Otros cientistas sociales argentinos consideran que la figura de la milonguita se construyó con propósitos pedagógicos y efectos moralizantes sobre las mujeres (Campodónico y Gil Lozano, 2000; Armus, 2002; Varela, 2005). Diego Armus (2002), por ejemplo, analiza que las letras de los tangos volcaron todo el peso de la tuberculosis en las mujeres y, especialmente, en la figura de la milonguita. Para Armus la tuberculosis apareció como la materialización de un castigo para las mujeres jóvenes de sectores populares, que osaban desafiar activamente su lugar en el mundo doméstico y barrial.

Marta Savigliano (1994), por su parte, propone analizar las letras de tango sobre milonguitas como una lucha de poder entre varones y mujeres. Dice que los escritores varones se quejaban de los engaños sufridos en manos de milonguitas crueles, malas, traidoras y ambiciosas porque, en la realidad, ellas detentaban una presencia activa, rebelde y capaz de desafiar la normatividad de género de la época. Afirma que estas mujeres -que solían ser identificadas por su etnicidad: "la tana" Paulina, "la china" Joaquina, "la rubia" Mireya, "la parda" Flora- ponían en juego identidades ambiguas, confusas e inestables frente a los parámetros de la mentalidad burguesa, que buscaba establecer identidades femeninas y masculinas claras, fijas y compactas.

Más allá de las interpretaciones particulares sobre las letras de tango en este contexto, la asociación que se establece entre baile y agencia femenina es similar en todos los casos. Ir a bailar tango es lo que convierte a las mujeres jóvenes en milonguitas: las pierde moralmente, las vuelve egoístas, hedonistas, indecentes y malvadas. Por eso, los castigos parecen justificados en el plano moral. Sin embargo, "dentro del modelo general de castigo a toda forma de agencia femenina, parece atinado afirmar que lo que se castiga es tanto la transgresión moral como el exceso de agencia" (Ortner, 2006: 164).

Durante la década de 1920 la madre se presenta como la contracara de la milonguita en las composiciones de tango. Es una mujer buena, circunscripta al ámbito doméstico y asociada con el trabajo a destajo desde la casa como costurera o lavandera, por ejemplo. La madre es una mujer abnegada, pasiva, consagrada a su familia y al trabajo doméstico -ya sea remunerado o no remunerado- y al cuidado de los demás. Es una madre amorosa e incondicional y, por sobre todas las cosas, completamente asexuada y sin deseos personales. En estas letras, también escritas por varones, la desilusión que produce la vida se resuelve con el regreso al lugar del que nunca se debió partir: la casa materna (Varela, 2005). Algunos de los tangos que se refieren a estas madres abnegadas son Madre (1922); Tengo Miedo (1928) y Madre hay una sola (1930) (Lamas y Binda, 1998).

El contrapunto entre la madre y la milonguita aparece con claridad en la letra de Margot (1921), composición 
en la que el escritor Celedonio Flores culpa a Margarita por su propia "caída" moral. Le reprocha su ambición y la acusa de haberse dejado engañar por los lujos y los piropos de los "muchachos seguidores", abandonando a su madre a su propia suerte. La madre, por su parte, aparece asociada al trabajo a destajo desde la casa, lavando ropa para poder subsistir:

Ahora vas con los otarios ${ }^{2}$ a pasarla de bacana a un lujoso reservado del Petit o del Julien, y tu vieja, ipobre vieja! lava toda la semana pa' poder parar la olla, con pobreza franciscana, en el triste conventillo alumbrado a kerosén. (Letra: Celedonio Flores. Música: José Ricardo).

En la mayoría de las letras de este período, madre y milonguita se presentan como dos figuras completamente escindidas: una madre que es pasiva, que no sabe de bailes, noches, placeres, deseos o proyectos personales y una milonguita que es activa, que no conoce el amor verdadero, la entrega, que se pierde entre los lujos, el baile del tango, los planes egoístas y los placeres mundanos.

Esta milonguita termina condenada a la soledad, a una vida miserable y desdichada, que además es el resultado de sus malas decisiones. Una excepción a esta narrativa la constituye la letra del tango Los cosos de al lao ${ }^{3}$, que fue compuesto por Marcos Larrosa en la década de 1940. Este tango narra cómo un grupo de vecinos baila y festeja la vuelta al barrio de una milonguita convertida en madre soltera:
¡Ha vuelto la piba
que un día se fuera
cuando no tenía
quince primaveras!
¡Hoy tiene un purrete...
y lo han bautizao!
Por eso es que bailan
los cosos de al lao.
(Letra: Marcos Larrosa. Música: José Canet).

La vuelta al barrio y al hogar quedan asociadas a la redención de "la piba que un día se fuera" del mundo doméstico como destino para perseguir sus propios proyectos. Más aún, la redención de la milonguita solo es posible porque ella vuelve con un "purrete" ${ }^{\text {, convertida }}$ en madre.

Al distribuir agencia de maneras específicas entre estas figuras femeninas, las narrativas analizadas refuerzan el argumento de que el baile del tango y la maternidad son incompatibles, al punto de fabricar personas distintas:

\footnotetext{
2 Otario es un término lunfardo que se utiliza para nombrar a una persona con escasa inteligencia. Bacana se refiere a una persona adinerada o con gustos refinados.

3 Aquí puede escucharse una versión interpretada por Luis Cardei: http://www.todotango.com/musica/tema/683/Los-cosos-de-al-lao/ 4 La palabra purrete significa bebé o niño pequeño en lunfardo.
}

por un lado, la madre, el barrio, la decencia, el hogar, la pasividad, el trabajo doméstico y la abnegación; y por otro, la milonguita, el baile del tango, el cabaret, la decadencia moral, la actividad, los lujos y los placeres. La milonguita sacrifica la familia y el amor romántico por su deseo de ascenso social, utilizando el baile a su favor. La madre sacrifica todo lo demás por amor a sus hijos.

\section{Un tango más: la historia de María Nieves Rego}

El 25 de febrero de 2019 Melina Brufman -bailarina de tango, coreógrafa, doula y madre de dos niños pequeñosmencionó a María Nieves durante la presentación de los resultados de una encuesta realizada a treinta y siete bailarinas de tango que son madres, con el objetivo de relevar su situación. Durante la charla, que fue organizada por el colectivo Trabajadorxs del tango danza (Ttd) en un centro cultural del barrio de Palermo, se discutieron diferentes temas vinculados a la desigualdad laboral entre varones y mujeres dentro de este circuito cultural. El foco estuvo puesto en la maternidad gestante, la crianza temprana y el cuidado infantil. Al comienzo, Melina reflexionó:

es algo que me llama mucho la atención, la cantidad de mujeres del tango que no son ni serán madres. A mí me gustaría saber cuántas de esas mujeres lo tienen bien resuelto desde el deseo. Quiero decir, que ellas hayan deseado que su vida vaya por otro lugar y hayan tenido bien en claro que no iban a ser madres. O a cuántas les pasó como a María Nieves... Esa es una pregunta que obviamente es muy personal, pero algo en mí empieza a unir el caminito de que la falta de sostén hace que muy pocas mujeres nos atrevamos a ponerle el pecho a la maternidad, con mucha incertidumbre (Nota de campo. 25 de febrero de 2019).

La historia de María Nieves Rego circulaba entre estas mujeres con una fuerza performativa impactante, como un ejemplo de renuncia a la maternidad, de consagración al baile y de entrega sentimental que no querían repetir para sí mismas. "Yo no quiero que me pase como a María Nieves", decían muchas bailarinas de tango durante nuestras conversaciones informales. Solían colocar a la artista en la categoría de una heroína-víctima (Ortner, 2006) del tango: si bien ella era la protagonista de la historia, el relato avanzaba impulsado por las cosas malas que le sucedían y no porque ella iniciara las acciones.

María Nieves tenía apenas nueve años cuando empezó a trabajar como empleada doméstica. Abandonó la escuela primaria para trabajar cama adentro en una casa de San Isidro. Al poco tiempo, la madre la sacó de ahí por los maltratos y los golpes que recibía por parte de su empleadora. Después siguió trabajando de lo mismo, pero en lugares donde la trataban mejor y podía volver a 
dormir a su casa (Entrevista a María Nieves Rego. El País, 7 de mayo de 2017).

En el documental Un tango más (2015) ella dice que, mientras limpiaba, "paraba la oreja" cada vez que escuchaba un tango en la radio. Recuerda que se le "iban las piernas", "agarraba una escoba y la abrazaba, me ponía a caminar de un lado al otro".

La historia de María Nieves Rego tiene casi todos los condimentos de la milonguita, pero comienza en la década del cuarenta: la "época de oro" del tango retratada como su período de máximo esplendor entre 1940 y 1950-. Hija de inmigrantes gallegos analfabetos, nació en 1934 en un conventillo del barrio porteño de Saavedra. Su padre era violento y su madre vivía sometida. Él trabajó como repartidor de leche, hasta que murió de tuberculosis a los 45 años. Desde entonces, la madre y los mayores de los cinco hermanos tuvieron que salir a trabajar para "parar la olla" (Entrevista a María Nieves Rego. El País, mayo de 2017).

A los once años, Nieves empezó a acompañar a la milonga ${ }^{6}$ a su hermana mayor, la Ñata. En la película cuenta que al principio iba solo a mirar, porque todavía no la dejaban bailar. También relata todos los detalles de la primera vez que vio a Juan Carlos Copes -con quien formaría una de las parejas más emblemáticas de la historia del tango-: fue en 1947, en el club Estrella de Maldonado ${ }^{7}$. Cuenta que sacó a bailar a la Nata, su hermana, que era una gran milonguera. También dice que Copes era muy lindo, pero un patadura: "al principio era un carrito. Así se decía en la milonga. La palabra carro era que no sabía bailar".

Esa noche, Nieves se fue a dormir pensando en él. No lo vería más por un tiempo, un año más o menos. Se volvieron a cruzar en el club Atlantå. Ella tenía catorce años. Él era tres años mayor y ya bailaba más: "sin pasos difíciles, pero ya sabía manejar a una mujer con soltura". Le pidió permiso a la Ñata para sacar a bailar a Nieves: "él fue vivo, se ganó la confianza de ella... A los pocos meses le volvió a pedir permiso, pero para que seamos novios" (María Nieves Rego. Un tango más, 2015).

Esta práctica de regulación de la sexualidad femenina

5 El documental fue escrito y dirigido por Germán Kral y producido Wim Wenders. La música está a cargo de Luis Borda, el Sexteto Mayor y Gerd Baumann. En la película se entremezclan escenas documentales con escenas de ficción. Mientras, se comparten conversaciones con María Nieves Rego y con Juan Carlos Copes. Todas las citas textuales utilizadas en este apartado fueron extraídas de este documental.

6 Espacios sociales, físicos y convencionalizados en donde las personas se reúnen a bailar tango (Carozzi, 2015).

7 El Club Social y Deportivo Estrella de Maldonado se fundó en 1934 y está ubicado en el barrio porteño de Palermo.

8 El Club Atlético Atlanta es una institución social, cultural y deportiva ubicada en Villa Crespo. Fue fundado el 12 de octubre de 1904. En estos clubes sociales se escribió gran parte de la historia del tango en Buenos Aires y, como dice Gálvez (2009), merecen una historia que aún no se escribió era muy habitual en los bailes sociales organizados en los clubes de barrio. Eduardo Gálvez (2009) comenta que las madres solían acompañar a sus hijas para cuidarlas al costado de la pista -en el caso de María Nieves, ese rol estaba representado por la hermana mayor-. Al advertir algún gesto indecente de un bailarín, las madres convocaban a organizadores o censores de pista para que contuvieran a los "eróticos incorregibles".

Los censores eran varones que tenían que controlar la pista de baile y evitar cualquier gesto o movimiento considerado fuera de lugar, ya sea por su indecencia o falta de decoro. Frente a alguna manifestación indebida, el censor retiraba a la pareja de baile de la pista y los advertía de ser echados del lugar para siempre (Savigliano, 1995; Pujol, 1999; Gálvez, 2009).

Gálvez (2009) ubica a las madres en el contexto del baile social, pero considerándolas exclusivamente en su rol de acompañantes, encargadas de regular la sexualidad de sus hijas y de prevenir cualquier manifestación erótica durante el baile. No sabemos si estas mujeres, además de controlar a sus hijas, participaban bailando de los eventos musicales -como lo hacía, por ejemplo, la hermana de María Nieves-.

María Julia Carozzi (2015), por otro lado, nos ofrece algunos elementos para complejizar el análisis de lo que efectivamente sucedía en las pistas de baile entre las décadas del cuarenta y cincuenta respecto a las sexualidades. La autora analiza como, a la par que se condenaban moralmente una serie de movimientos y de acercamientos en los bailes con orquestas en vivo desarrollados en los clubes de barrio, funcionaban de modo paralelo otros espacios de baile -ubicados en las confiterías del centro porteño-, en los que esas reglas eran subvertidas por completo. Es decir, en las confiterías del centro el contacto físico estaba permitido y no era regulado.

Según recupera Carozzi (2015) a partir de una serie de entrevistas, incluso era posible aspirar a entablar vínculos sexuales pasajeros con las mujeres que asistían a estos lugares. De esta manera, muestra que las prácticas sexo-afectivas de las mujeres que bailaban tango en Buenos Aires durante este período eran mas complejas y heterogéneas que las políticas narrativas que buscaban distribuir agencia femenina de maneras específicas entre madres y milonguitas. Así, la autora nos invita a desconfiar de cualquier narración homogénea y unilineal sobre el desarrollo de una forma de baile y nos recuerda que es necesario ser escépticos en la utilización de registros históricos, ya que estos tienden a sesgar nuestra mirada y a ocultar la diversidad interna existente dentro de un mismo período.

En suma, reconocer el peso simbólico e ideológico de las narrativas de la madre y la milonguita de las letras de 
tango, no equivale a decir que las mujeres solo podían optar por convertirse en una de ellas. Con mucha claridad, Catalina Wainerman remarca que: "una cosa son las ideas, imágenes y representaciones que circulan en la sociedad y moldean las orientaciones de los individuos y sus comportamientos y muy otra son los comportamientos cotidianos; una el discurso y otra el quehacer diario" (Wainerman, 2005: 36).

Continuando con la esquematización de los perfiles protagónicos del documental Un Tango Más (2015), allí Juan Carlos Copes cuenta que él tenía una visión: quería hacer algo grande con el tango. Sabía que el baile sería el centro de su vida y soñaba con llevar el tango a los escenarios para bailarlo profesionalmente. En esos primeros abrazos con María Nieves, sintió que había encontrado a la mujer ideal para su proyecto: "encontré mi Stradivarius", comparte. Para Nieves, en cambio, todo empezó por amor: "Yo me había enamorado de él. Punto. Nada más. El baile era una excusa, ¿me entendés lo que te digo?... Iba a bailar porque era la alegría de los pobres, de ir a bailar sábado y domingo. Pero no me importaba mucho en sí el baile, sino la persona", comenta sobre cómo empezó la historia.

Por entonces, la pareja inició un intenso vínculo afectivo y dancístico. Bailaban juntos día y noche, practicaban pasos, inventaban secuencias y ensayaban con el objetivo de bailar profesionalmente. Un objetivo que al principio fue de él, pero que ella decidió acompañar y hacer propio. Fueron desarrollando, poco a poco, un estilo particular que incluyó la impronta personal de cada uno. En Un Tango Más (2015), detallan que en la milonga de Atlanta "gastaban la pista", que la gente se paraba a mirarlos: "teníamos algo especial, no sé... es inexplicable" -dice Nieves en el documental mientras pita la boquilla de un cigarro- "Éramos buenos, sí, pero además nos complementábamos... Yo creo que hasta influyó que él fuera morocho y yo de tez blanca. Fijate lo que te digo".

En el registro fílmico María Nieves se describe a sí misma como una "buena compañera" que siempre supo que él iba a lograr su objetivo, que confió en la tenacidad, la visión y el amor de Copes por el tango. Ella se muestra a sí misma como una mujer abnegada, enamorada, sencilla, naturalmente bella y bastante crédula, que tuvo el mérito de saber acompañar y nutrir el proyecto de su hombre, siempre desde las sombras. Él aparece como el ideólogo, el autor intelectual del proyecto profesional, el visionario que logró crear el producto de exportación y que diseñó sus primeras coreografías inspirado en los musicales hollywoodenses de Gene Kelly y Cyd Charisse.

En 1955 la compañía de tango escénico que armaron junto a otras parejas de bailarines sociales debutó en la calle Corrientes. Con el inicio de una exitosa carrera artística que duró cincuenta años -y que revolucionó la manera de bailar tango profesionalmente, llevándolo a los principales escenarios del mundo-, también comenzaron los intensos dramas de amor y desamor que marcaron toda la trayectoria profesional de la pareja. En 1965 Copes y Nieves se casaron en Las Vegas, "fuimos muy felices y también muy infelices. Él era muy pintón, las minas se le regalaban", confiesa Nieves en Un Tango Más (2015). Dice que el casamiento fue una sentencia de muerte para la historia de amor.

Mientras como pareja profesional estaban cada vez más amalgamados, como pareja sentimental las cosas no salieron como Nieves esperaba. "Solo yo sé las que pasé", recuerda:

Mi sueño era casarme y tener una familia con hijos. Sí, ¿cómo no? Mi sueño no era ser una artista. Jamás se me había pasado por la cabeza. Era tener un hogar con hijos. Pero salió todo al revés, viste. Todo al revés [...] Fue una actriz-cantante que había. Que me dijo, María, ¿vos sabías que Juan tiene un hijo con otra mujer? Y me mató. Te imaginás... Un hijo con otra mujer. Entonces se me vinieron a la cabeza mil cosas. Mil cosas. Va a pensar la gente que yo no le di un hijo, que por eso tiene un hijo con otra mujer. $Y$ me dio una bronca... pero tremenda. Tenía ganas de salir gritando. Porque mi orgullo se sintió herido (María Nieves Rego. Un tango más, 2015).

Según Nieves, esa separación sentimental significó un gran crecimiento para ella como artista: "estaba herida. Pero eso me ayudó a mí a subir. Porque yo siempre estaba debajo de él. Y yo me dije unas palabras: te voy a demostrar que te voy a revolcar por el escenario. Eso sí me lo acuerdo". Confiesa que el odio y la bronca fueron su motor arriba del escenario y que se convirtió en su mejor versión como bailarina. Quería mostrarle a Copes lo que era capaz de hacer, disputarle poder sobre el escenario.

Durante esta etapa, la pareja artística se consagró a nivel internacional con el espectáculo Tango Argentino, montado por el director Claudio Segovia. La obra se estrenó en 1983 en París y luego fue un éxito en Broadway: "nosotros seguimos bailando. No importa lo que pasó. Importa lo que hacés", reflexiona Nieves en el documental. Junto con otras frases como: "se puede separar lo artístico de lo personal. Se sufre, pero te hace crecer más como artista", "no va a llegar a haber, nunca más, una pareja de tango como la nuestra. Yo creo que fuimos la pareja del siglo veinte. Y del veintiuno también".

De manera similar a la política narrativa de las letras de tango sobre las milonguitas, el relato de María Nieves la presenta asumiendo una agencia activa en la primera parte de la historia. Ella logra avanzar impulsada por las desgracias que le suceden. En medio de una infancia atravesada por violencias y carencias de todo tipo, Nieves limpia casas para ayudar económicamente a toda su 
familia, pero también aprende a bailar tango -“es la única alegría para los pobres", dice ella- y se enamora de Juan Carlos Copes.

A partir de estos acontecimientos, la heroína-víctima toma las riendas de la situación y conduce su acción, embarcándose en la búsqueda activa de su deseo: renuncia a su trabajo como empleada doméstica, confía en el sueño de su compañero y lo vuelve propio y se dedica a mejorar su estilo de baile. De a poco, Nieves no solo logra vivir de bailar: se convierte en un ícono de este género artístico en todo el mundo y en un símbolo de erotismo y sensualidad.

Pero -y esto es decisivo en la política narrativa de género-, las mujeres demasiado hábiles y astutas reciben, invariablemente, un castigo por eso. Para Sherry Ortner (2006), todas las protagonistas de relatos que asumen una agencia activa, normalmente reservada a los héroes masculinos, terminan mal. Ellas se ven obligadas a renunciar, sistemáticamente, a su actitud activa y a la posibilidad de llevar a cabo sus proyectos personales.

Para convertirse en una bailarina exitosa con Copes, María Nieves tuvo que renunciar a su deseo de ser madre, soportar sus engaños sistemáticos y verlo formar la familia que ella soñaba con otra mujer. En una estocada final, Juan Carlos Copes decidió romper la sociedad laboral después de casi cincuenta años de bailar juntos: "sentí que me clavaban un puñal en el corazón... yo ya era grande, pensé que el tango se había acabado para mí... solo yo sé cómo caí. Y cómo me levanté después de tocar fondo", confiesa Nieves en Un Tango Más (2015). Para ella, esa fue la traición imperdonable. Pasó años sola y encerrada en su casa con una gran tristeza y sin saber qué hacer, hasta que le ofrecieron incorporarse al elenco de Tanguera, un musical producido por Diego Romay y con la dirección coreográfica de Mora Godoy. Recuerda que la primera vez que volvió a subirse al escenario tenía miedo y que cuando la gente estalló en una ovación pensó, incrédula: "¿Me aplaudirán porque me tienen lástima?".

Según Ortner, las mujeres demasiado agentivas -o activassuelen recibir un castigo, ya sea por su transgresión moral o por su exceso de agencia. Si pensamos en el caso de María Nieves, la renuncia impuesta a la maternidad, la condena a retirarse temporalmente del tango y la inesperada soledad durante su vejez aparecen como una especie de castigo, un precio que la milonguera tuvo que pagar por sus peligrosas elecciones de vida "tuve que elegir y elegí el tango", dice ella. En el documental también insinúa haber abortado durante la adolescencia:

Ojo que yo podía tener hijos. Porque por ahí la gente pregunta. Y bueno, ella no tuvo hijos. ¿Cómo se llama cuando uno no tiene? Estéril. No... Si yo ahora, en este momento, tengo quince o dieciséis años y quiero tener un hijo, lo tengo. Y en mi casa me van a abrir las manos y en el barrio no voy a ser mal mirada... Pero en mi época, eso era tabú. Pero sí... podía tener-Nieves hace una larga pausa, mientras mira fijo a su interlocutor. Tiene una mirada cómplice, un gesto que deja entrever que hay algo más detrás de sus palabras-, pero hasta ahí te puedo decir. Nada más (María Nieves Rego. Un tango más, 2015).

La historia de María Nieves circula entre las bailarinas profesionales de tango hasta la actualidad. Para muchas, es una narrativa ejemplificadora. Se trata de una historia de éxito profesional y de renuncia personal que no quieren repetir en sus proyectos vitales. En el documental, Nieves comparte:

No estoy arrepentida. La vida vino así. La acepté así. Y la seguí así. Y no puedo arrepentirme de todo. Por eso, yo les aconsejo a las chicas jóvenes, que se casan y son tangueras, que no dejen de tener un hijo. Porque el tango puede esperar dos, tres y cuatro años. Porque son jóvenes. Porque cuando se quieran acordar, ya es tarde. Eso me pasó a mí (María Nieves Rego. Un tango más, 2015).

Durante el documental esta milonguera rompe el silencio sobre su propia historia y reflexiona públicamente sobre un ideal de amor romántico que la circunscribió a un lugar de heroísmo generizado en términos de sufrimiento, paciencia, consagración y postergación de sí. Aquí comparte las injusticias que padeció y dice -al menos entre líneas- que el precio que le impusieron -tanto el éxito profesional como el ideal de amor romántico-, fue demasiado alto para ella. Por eso, necesita recordarle a las más jóvenes que hay otros caminos posibles, que no es necesario renunciar a todo lo demás por amor -al tango o a un hombre- y que, si la maternidad se ubica dentro de sus deseos y proyectos construidos culturalmente, pueden encontrar el modo de ensamblar su rol como madres con su rol como bailarinas dentro de un mismo proyecto personal.

\section{Lucía y Catalina: entre ser madres y ser bailarinas}

Lucía y Catalina son amigas y bailarinas profesionales de tango. Las dos trabajaron durante muchos años en shows para turistas extranjeros. Lucía tiene 40 años, vive con su pareja y sus dos hijos pequeños en el barrio de Villa Urquiza. Catalina tiene 28 años y vive en Almagro con su marido y sus tres hijos. Al recapitular sobre sus primeros embarazos durante una serie de entrevistas realizadas entre 2015 y 2016, estas mujeres contaron como sintieron que la tensión entre las representaciones de la madre y la milonguita se encarnó en su imagen corporal:

Cuando yo estaba embarazada de seis meses 
trabajaba en un espectáculo en la plaza. Me revoleaban por todos lados y las señoras gritaban "no nena, cuidado, que lo vas a parir acá". Pero hasta los seis meses. Después ya dije, bueno, ya está. Ya no es nada sensual esto, con la panza. Porque yo me hacía la sexy con la panza [...] me acuerdo que había un tango que era súper como la mujer y el hombre, de seducción. Y la panza daba otra cosa. Con el vestido apretado y las medias de red, era como medio raro, como que mucho no se relacionaban. Lo que pasa es que en ese momento era un show para extranjeros, que era lo que se vendía (Entrevista a Catalina, 8 de septiembre de 2015).

Me acuerdo cuando me bajé del escenario, que estaba embarazada. Yo sentía que podía seguir bailando, porque físicamente podía [...] pero ya se me empezaba a notar. Y me acuerdo que un día me bajé, casa bien de turistas y que se yo, y una turista de Brasil viene y me dice: ay, vos sos la que baila embarazada, iqué lindo! Y ahí dije bueno, me voy. Termino esta semana. De hecho, adelanté bastante, porque yo quería seguir bailando todo el quinto mes, ya estaba cumpliendo el quinto mes, veinte semanas y ya se me notaba. Evidentemente la gente ya se daba cuenta. Y no daba. No daba porque no tenía un lugar [...] era como, no, hay una gorda en el escenario con un bebé. No daba. Entonces te genera un parate importante. $Y$ es un parate también interno. $Y$ es tu cuerpo, que siempre fue tu herramienta para bailar, que ya no es tuyo. Estás realmente tomada por el bebé (Entrevista a Lucía, 15 de marzo de 2016).

Vale la pena detenerse por unos instantes en las imágenes que ofrecen Lucía y Catalina en sus narraciones. El vestido apretado y las medias de red que describe Catalina nos remontan visualmente a la idea estereotipada de la milonguita en el tango. Esta imagen apela a una exposición erotizada del cuerpo femenino vinculada a un tipo de deseo heterosexual. Claro que esta relación entre vestimenta, identidad de género, deseo y orientación sexual no es en absoluto autoevidente, sino que se trata de una lectura visual construida a lo largo del tiempo a partir de procesos de apropiación de imaginarios y sentidos sedimentados que dialogan con la política narrativa analizada en el primer apartado.

Por su parte, las menciones a la "panza" y a la "gorda con bebé" nos trasladan a la dimensión reproductiva de la sexualidad femenina. Las curvas y las redondeces del cuerpo de una mujer son leídas como propias de un cuerpo gestante. Al igual que sucede con la imagen de la milonguita, la del embarazo también fue construida e interpretada culturalmente, encarnando en el cuerpo gestante valoraciones culturales y normatividades sociales.
Para Lucía y Catalina mezclar el vestido apretado y las medias de red con las curvas del cuerpo gestante, especialmente ante los turistas extranjeros, "no daba" o era "medio raro". Las dos estaban convencidas de que no había lugar para ellas sobre el escenario y consideraban que la imagen híbrida entre la madre y la milonguita no era posible ni podía ser bien recibida por las personas que asistían al espectáculo.

El embarazo no tenía lugar porque la historia coreográfica que se quería contar era otra. Era una historia de seducción, de sensualidad, de deseo, de erotismo y de tensión sexual entre un hombre y una mujer. Una historia que recreaba desde diferentes elementos visuales el supuesto origen de la historia del tango (Carozzi, 2015) como un baile de prostitutas y compadritos.

Este mismo vínculo entre tango y prostitución ha sido narrado, una y otra vez, por la literatura en general y por las ciencias sociales en particular, "ya sea como supuesto origen en la historia de su desarrollo, o como consecuencia para la vida de los personajes femeninos de origen humilde que lo bailan en los cabarets en los años del centenario" (Carozzi, 2015: 209).

María Julia Carozzi (2015) dice que la insistencia en la figura de la milonguita, junto con las múltiples investigaciones que fijan su atención en el período que va de 1910 a 1920, ya sea en la música o en el baile, contribuyeron a vincular de un modo estrecho y unívoco los devenires del baile social con el proceso de normalización de la sexualidad femenina desplegado en la sociedad argentina desde finales del siglo diecinueve.

En cambio, ella asegura que estas interpretaciones materializaron un guion histórico. Una narrativa que presenta de un modo demasiado lineal los cambios acontecidos, relatando algunos aspectos de la ejecución del baile, eliminando otros y ocultando los diferentes contextos en los que también se bailaba tango durante esta etapa. Podría decirse que el devenir del baile social habitualmente se relata, casi sin fisuras, hacia una misma dirección: de la barbarie a la civilización, con escala en París.

Según esta narración, el tango nace marginal y gozoso entre las paredes de los prostíbulos porteños para luego viajar a París, donde se consagra y regresa decente y purificado. A partir de este viaje, el tango, tanto en sus letras como en su baile, incorpora la mentalidad burguesa de las elites transnacionales y los valores morales propiciados por el higienismo y por el positivismo de la generación del ochenta.

De tanto "narrarlo, ilustrarlo e interpretarlo, el derrotero de ida y vuelta del baile a Europa se ha cristalizado como el recorrido dominante, desde el que se percibe y concibe su desarrollo, hasta adquirir la solidez del asfalto" (Carozzi, 
2015: 81). En este sentido, la autora cuestiona la gran concentración de estudios que se preguntan por las primeras dos décadas del siglo veinte y que se focalizan en los prostíbulos, los salones europeos y las elites locales, dejando a un lado otros análisis posibles, ya sea de otras etapas de desarrollo de este baile o de otros contextos en los que también se bailaba tango durante ese mismo período.

Al pensar esta práctica narrativa ritualizada desde el movimiento y la pautación coreográfica, se observa que el vínculo entre el tango y la prostitución es recreado permanentemente sobre el escenario. Casi en cualquier historia que se quiera contar, la bailarina aparece evocando, con sus movimientos y con su vestuario, a la supuesta milonguita de antaño. La representación erótica del cuerpo femenino es "lo que vende" en los shows para turistas y las bailarinas deben escenificar un modo sensual de feminidad diseñado para ser consumido, principalmente, por hombres (Savigliano, 1995).

Lucía y Catalina sentían que interpretar a esa "mujer fatal" sobre el escenario estando embarazadas era motivo de vergüenza e incomodidad. Afirmaban que con un abdomen prominente no podían encarnar ese juego coreográfico de seducción montado sobre tacones, medias de red y vestidos apretados. Les parecía algo completamente fuera de lugar, impensable.

Antes de ser madres, estas bailarinas se habían sujetado sin mayores inconvenientes a las reglas coreográficas del tango escénico y habían (re)encarnado sobre el escenario determinadas relaciones de género y eróticas que hacían visibles, para sí mismas y para el publico que asistía a los espectáculos, determinadas dimensiones de su feminidad (Blázquez, 2014).

Al momento de devenir madres, en cambio, la escenificación de la milonguita y de la atracción erótica heterosexual se volvió un problema. Su profesión como bailarinas era puesta en cuestión porque existía un juego erótico que ya no podían o no querían jugar estando embarazadas. Las dos consideraban que el motivo era bastante autoevidente: no se puede ser madre y milonguita, todo a la vez. A Lucía esta sensación de incompatibilidad se le potenció durante el puerperio, dificultando su posibilidad de "ponerse las medias y dar la teta al mismo tiempo":

tuve que volver a bailar y estaba muy, bueno era primeriza, ¿no? Pero tenía una idea, muy idealizada, de bueno, yo voy a volver, mi vida, yo amo lo que hago y etcétera. Y lo que me encontré fue que no me hallaba para nada haciendo lo que siempre había hecho. Pero para nada. Me sentía un poco más un payaso. No tenía que ver con nada. Ya había bajado lo que tenía que bajar. Ya había vuelto a entrar en los mismos vestidos. Todo estaba igual, pero yo no estaba igual. Sobre todo, en relación a lo que se representaba como ícono de la feminidad. En mi pareja de baile yo decía, no, esto no, esto no es más. Estoy interpretando a otra persona que no soy yo. No es que yo no me sentía lista para bailar (Entrevista a Lucía, 15 de marzo de 2016).

La subjetividad de Lucía se había transformado con la maternidad y este cambio era tan profundo, que ya no se sentía cómoda interpretando los mismos papeles ni recreando los mismos juegos de seducción sobre el escenario. Sus proyectos e intereses habían cambiado. Ella estaba lista para volver a bailar, pero no quería seguir contando la historia de la milonguita, no quería representar a la "mujer fatal" ni entrar en los mismos vestidos que usaba antes de ser madre, porque al hacerlo se sentía "poco más un payaso".

Como en las narrativas de las letras de los tangos de la década del veinte, en sus relatos la madre aparecía en las antípodas de la milonguita. Para Lucía era muy difícil pensar que ambos estereotipos pudieran convivir en un mismo cuerpo de mujer. La madre y la milonguita se tensionaban en la subjetividad de esta bailarina y configuraban una relación contradictoria, que generaba diversos replanteos personales y un sentimiento de profunda incompatibilidad entre la maternidad temprana y la profesión.

Como puede observarse a partir de estos relatos, las narrativas de la madre y la milonguita, así como la relación antagónica entre ambas figuras, continúan siendo efectivas en la medida en que todavía logran moldear, organizar y dar sentido -al menos en parte y disputando con otros sentidos- a las representaciones de estas mujeres. Aún existe una gran potencia simbólica en estas figuras femeninas del tango; que continúan participando en "el trabajo cultural que se requiere para construir y distribuir agencia como parte del proceso de construcción apropiada de individuos con género, y, en consecuencia, empoderados de modo diferencial" (Ortner, 2006: 162).

Por último, es importante destacar que las prácticas -y los sentidos de la acción- se encuentran atravesadas por diferentes repertorios culturales que se tensionan, confrontan o negocian en cada contexto específico. Por tanto, la capacidad de estas narrativas para afectar imaginarios, sentidos y representaciones no se traduce, de un modo directo y lineal, en lo que las bailarinas de tango hacen efectivamente en sus vidas diarias. Tampoco en sus deseos y proyectos personales.

\section{La redención de la milonguita sobre el escenario}

Cierto viernes fui a la segunda función del ciclo Berretín: Arrebato tanguero en cuatro movimientos, que se presentó durante todos los viernes de junio de 2015 
en el área de danza del espacio cultural El Sábato, dependiente de la Universidad de Buenos Aires ${ }^{9}$. El ciclo estaba compuesto por cuatro piezas breves que convivían y dialogaban entre sí: Fragmento de un elogio, Ensayo 1, Habita Dos y Cuatro Noches.

La noche de la función, Habita Dos concentró toda mi atención. Para mi sorpresa Melina Brufman, su creadora y directora, protagonizaba la pieza con un embarazo de cinco o seis meses de gestación, bailando en compañía de Guadalupe Ponzelli y John Galindo. Durante los primeros minutos de la coreografía las dos mujeres bailaron juntas. Mezclando los lenguajes del tango y la danza contemporánea, las artistas generaron un momento íntimo, sensual y amoroso con el embarazo en un lugar central. Luego, aparecía en escena John Galindo y la historia se transformaba, encausándose por canales coreográficos más predecibles y compartidos dentro del tango escénico: la mujer embarazada y el varón bailaban juntos, en los roles tradicionalmente asociados con ambos géneros ${ }^{10}$, y la otra mujer se retiraba completamente de la escena.

Unos meses más tarde, con Habita Dos todavía en mi mente, encontré una nota que Melina Brufman publicó en octubre de 2012 para la revista El Tangauta con motivo de los festejos del día de la madre. Allí la bailarina compartía algunas ideas sobre transformaciones personales asociadas con la llegada de su primer hijo y entrevistaba a otras dieciséis profesionales del tango, madres de por lo menos un hijo o hija o embarazadas, que también ponían en común algunas dimensiones de sus vivencias. Asimismo, Melina reflexionaba sobre sus procesos creativos:

Es posible que esté atravesando una crisis artística. A partir de Dante, mi cabeza está en plena transformación. Pero supongo que esa también es una dirección: voy hacia lo desconocido. Una cosa se reveló con total contundencia: ahora lo más importante es disfrutar el "durante". En otros momentos me sentí muy atraída por otras dimensiones del "ser mujer": relaciones contradictorias, viscerales, en constante tensión con las energías del hombre. Esa tensión funciona muy bien dramáticamente en escena. Hoy me interesa explorar el "amor absoluto", qué historias surgen de esa energía, más pacífica, pero igual de

\footnotetext{
9 El área de danza está en el subsuelo de un edificio ubicado en la calle Uriburu al 763. El Sábato, Área Danza

[ https://elsabatodanza.wordpress.com/2015/05/23/berretin/ ] (Última consulta: 5 de mayo 2021)

10 En la enseñanza y el baile del tango suelen distinguirse dos roles: una persona es la encargada de "llevar", "guiar" o "marcar" los pasos y la otra debe aprender a "seguir" o "dejarse llevar". Históricamente, ha existido una asignación fija del rol durante el baile en función del sexo y el género del bailarín: los hombres llevaban y las mujeres, seguían. Esta relación se ha desestabilizado de manera creciente a partir de la primera década del nuevo siglo, principalmente gracias a las propuestas de tango queer y tango gay (Liska, 2018).
}

arrasadora (Melina Brufman. Revista El Tangauta, octubre de 2012).

A partir de la gestación, el parto y el puerperio de su primer hijo, Melina había experimentado una transformación de su subjetividad y sentía que su carrera coreográfica no era ajena a este proceso de profundas modificaciones. Así, la maternidad se imbricaba de diversos modos con su rol como coreógrafa y bailarina, modificando sus horizontes creativos y su mirada artística, llevándola a vincularse con nuevas dimensiones de su feminidad.

Igual que Melina, durante mi etnografía otras mujeres mencionaron una necesidad de integrar la vivencia materna a sus procesos creativos y artísticos. La maternidad se convertía, así, en una oportunidad para entenderse mejor a ellas mismas, para repensar el lugar que ocupaban en el tango escénico o para reflexionar sobre las representaciones femeninas dominantes en estos espacios. Si bien muchas no se referían directamente a los estereotipos de la madre y la milonguita, sus menciones a la mujer "fatal", al "deseo" y a la "pasión" me remitían inmediatamente a estas figuras y a las tensiones entre el deseo sexual y el "amor puro" de la madre.

En el caso de Melina, la transformación personal asociada a la maternidad le permitía cuestionar los cánones estéticos impuestos hacia las mujeres en su profesión. Por eso, durante su segundo embarazo procuraba visibilizar su cuerpo gestante como parte de una modalidad de acción desplegada sobre el escenario. Para esta artista, el embarazo no era solo una limitación para poder bailar ni un estado a partir del cual tenía que renegociar su lugar en el espacio social. Se trataba, además, de una experiencia vital que le permitía ampliar los temas, las miradas y las emociones que se ponían en juego en sus coreografías.

Motivada por el interés de trazar puentes y canales de comunicación entre los "nuevos mundos" que la constituían, Melina rechazaba la idea de seguir contando las mismas historias de seducción, erotismo y tensión heterosexual sobre el escenario. El estereotipo coreográfico de la milonguita formaba parte de su pasado y la "energía arrasadora" de la maternidad traía consigo la necesidad de buscar otros rumbos, de contar nuevas historias, de narrar otros vínculos de "amor absoluto" y de hablar sobre las relaciones de sostén o afectividad entre mujeres.

Entendida como una forma de agencia social, la propuesta coreográfica de Melina deslizaba otras miradas sobre la sexualidad femenina, al tiempo que habilitaba a su creadora a dar un nuevo sentido a su biografía y a sortear algunas de las múltiples dificultades impuestas por su profesión. Se trataba de una búsqueda que intentaba utilizar la maternidad positivamente, productivamente, plasmándola en una propuesta coreográfica o en la estética de una obra. Es decir, si bien la maternidad 
continuaba sin tener un lugar propio dentro del tango, esta bailarina madre se las ingeniaba para fabricarlo momentáneamente, haciéndolo y deshaciéndolo sobre el escenario.

A partir de retomar la idea de narrativa de la redención propuesta por McGannon, Curtin, Schinke y Schweinbenz (2012) para el análisis del caso de Paula Radcliffe, una famosa atleta británica especialista en pruebas de fondo, observo que para bailarinas como Melina la maternidad constituía una oportunidad excepcional para redimir a la milonguita sobre el escenario. Esta redención puede interpretarse en dos sentidos.

Por un lado, como una narración en la que se refuerzan los modelos ideales, las normas sociales y los mandatos morales vinculados a la maternidad, ya que se postula que la milonguita que deviene madre se "purifica" y se conecta con lo "verdadero": sentimientos genuinos y lazos de amor que perduran en el tiempo. De esta manera, se renueva el mensaje de que la verdadera vocación de toda mujer es la materna y la idea de que ese es el camino correcto, incluso para aquellas mujeres que durante un tiempo se dejaron engañar por los placeres de la carne, los lujos, la banalidad, la noche, el baile y los falsos amores.

Por otro, la narrativa de la redención también puede pensarse como una modalidad de acción que interpela los estereotipos de la madre y la milonguita que continúan vigentes - de diferentes maneras y en diversos grados-en el tango y que las presentan como dos figuras antagónicas, incompatibles y mutuamente excluyentes. Partiendo de esta segunda interpretación es posible observar cómo la coreógrafa de Habita Dos fue capaz de seleccionar, según sus propios criterios, diversos fragmentos de los discursos, las representaciones y las narrativas dominantes para disputarlos a partir de su hibridación.

De este modo, la yuxtaposición de los estereotipos le permitió componer una historia original, en la que el cuerpo visiblemente gestante de su protagonista era capaz de encarnar las contradicciones entre la milonguita y la madre sobre el escenario. Aquí la milonguita ya no aparecía representada como una figura femenina condenada a la soledad, a la tristeza y a la desdicha, mientras que la madre se insinuaba como una mujer sexuada, conectada con el propio disfrute y con el placer gestante.

Al intervenir en un festival de tango alternativo en Buenos Aires, Melina desbordaba momentáneamente los cánones estéticos y los límites -simbólicos y materiales-impuestos al embarazo por su profesión. Gracias a esta modalidad de acción, ella lograba habitar los márgenes del discurso dominante para incluir, desde ahí, otras historias. Narraciones que comenzaban a disputar las fronteras de inteligibilidad del tango bailado coreográficamente.

\section{Conclusiones}

En este artículo se analizaron dos políticas narrativas que participan en la construcción de agencia de las bailarinas de tango: la idea de que existe un castigo inexorable para las mujeres demasiado agentivas -un precio que hay que pagar- y la idea de que hay una incompatibilidad inherente al baile del tango con la maternidad.

Como en los casos de Lucía y Catalina, para otras bailarinas que participaron de mi etnografía las tensiones entre la milonguita y la madre se encarnaban en su imagen corporal durante sus embarazos y puerperios, llevándolas a pensar que no era posible "ponerse las medias de red y dar la teta al mismo tiempo". Estas narrativas continuaban operando en sus subjetividades a través de representaciones que entraban en tensión, de diferentes maneras $-y$ en diversos grados-, en sus prácticas cotidianas.

Estas tensiones generaban, por momentos, un sentimiento de profunda incompatibilidad entre la maternidad y el tango. La noche, la seducción, el erotismo, la vestimenta o el baile de pareja solían figurarse como contradictorios e incompatibles con la maternidad temprana; manifestando diversos desajustes entre representaciones, sentidos, imaginarios y prácticas cotidianas.

De todas maneras, al igual que el peso simbólico y psicológico de la maternidad intensiva o abnegada no se traducía sistemáticamente en las prácticas de estas bailarinas de tango, en sus posibilidades de acción y en sus dinámicas familiares -todas ellas trabajaba por lo menos medio tiempo y el modelo de cuidado infantil en los hogares heteroparentales tendía a ser cada vez más compartido, solo por mencionar dos ejemplos-; el peso simbólico de la figura de la milonguita no significaba que, al momento de ser madres, las bailarinas del circuito cultural del tango abandonaran automáticamente su profesión.

Es decir, la sensación de extrema incomodidad que muchas vivenciaban luego de ser madres no las alejaba por completo del tango. Por el contrario, en ocasiones las llevaba a bucear en otras alternativas posibles, a ejercer diversas modalidades de acción para ocupar los espacios o a disputar sentidos sobre el escenario. A encontrar pequeños desplazamientos, intersecciones o cruces de frontera.

No obstante, estas narrativas operaban en términos de representaciones e imaginarios en las subjetividades de muchas mujeres, potenciando sensaciones de desajuste e incompatibilidad dentro de sus proyectos personales y dotando a sus prácticas de sentidos diversos que se negociaban, se tensionaban o se confrontaban en cada contexto particular. 


\section{Bibliografía}

Archetti, Eduardo (2003). Masculinidades. Fútbol, tango y polo en la Argentina. Buenos Aires: Antropofagia.

Armus, Diego (2002). "'Milonguitas' en Buenos Aires (1910- 1940): tango, ascenso social y tuberculosis". En História, Ciências, Saúde Manguinhos (9), 87- 207.

Blázquez, Gustavo (2014). ¡Bailaló! Género, raza y erotismo en el Cuarteto Cordobés. Buenos Aires: Gorla.

Campodónico, Raúl Horacio y Fernanda Gil Lozano (2000). "Milonguitas en-cintas: la mujer, el tango y el cine". En F. Gil, V. Pita y M. Gabriela Ini (eds.) Historia de las mujeres en la argentina 2. Siglo XX. Buenos Aires: Taurus, 117- 136.

Carozzi, María Julia (2014). "Lo sexual es invisible a los ojos: exhibición erótica y ocultamiento de los vínculos sexuales en las milongas céntricas de Buenos Aires". En Versión. Estudios de Comunicación y Política. Nueva Época (33), 105- 118.

Carozzi, María Julia (2015). Aquí se baila el tango. Una etnografía de las milongas porteñas. Buenos Aires: Siglo XXI Editores.

Cosse, Isabella (2010). Pareja, sexualidad y familia en los años '60. Buenos Aires: Siglo XXI Editores.

Foucault, Michel (1992) [1977]. Microfísica del poder. Madrid: La Piqueta.

Gálvez, Eduardo (2009). “El tango en su época de gloria: ni prostibulario, ni orillero. Los bailes en los clubes sociales y deportivos de Buenos Aires, 1938-1959". En Nuevo Mundo Mundos Nuevos.

Imaz, Elixabete (2010). Convertirse en madre. Etnografía del tiempo de gestación. Madrid: Cátedra.

Lamas, Hugo; Binda, Enrique (1998). El tango en la sociedad porteña (1880-1920). Buenos Aires: Héctor Lorenzo Lucci Ediciones.

Liska, Mercedes (2018). Entre géneros y sexualidades. Tango, baile, cultura popular. Buenos Aires: Milena Caserola.

Mahmood, Saba (2008). "Teoría Feminista y el Agente Social Dócil. Algunas reflexiones sobre el Renacimiento Islámico en Egipto". En Cultural Anthropology 16 (2): 202-236.
McGannon, Kerry R.; Curtin, Kim; Schinke, Robert J.; et. al. (2012). "(De)Constructing Paula Radcliffe: Exploring media representations of elite running, pregnancy and motherhood through cultural sport psychology". In Psychology of Sport and Exercise (13), 820-829.

Ortner, Sherry (2016) [2006]. Antropología y teoría social. Poder y agencia. Buenos Aires: Unsam Edita.

Pujol, Sergio (1999). Historia del Baile. De la Milonga a la Disco. Buenos Aires: Emecé.

Sáez, Mariana Lucía (2017). Presencias, riesgos e intensidades. Un abordaje socio-antropológico sobre y desde el cuerpo en los procesos de formación de acróbatas y bailarines/as de danza contemporánea en la ciudad de La Plata. Tesis de doctorado, Facultad de Filosofía y Letras, Universidad de Buenos Aires.

Savigliano, Marta E. (1994). "Malevos llorones y percantas retobadas: el tango como espectáculo de razas, clases e imperialismo" En Revista Relaciones de la Sociedad Argentina de Antropología. Tomo 19, 79-104.

Varela, Gustavo (2005). Mal de Tango. Buenos Aires: Paidós.

Verdenelli, Juliana (2020). Entre crear y criar: balances entre la profesión y la maternidad de bailarinas de tango y bailarinas de contemporáneo en Buenos Aires. Tesis de Doctorado en Antropología Social. Instituto de Altos Estudios Sociales, Universidad Nacional de San Martín.

Wainerman, Catalina (2005). La vida cotidiana en las nuevas familias. ¿Una revolución estancada? Buenos Aires: Lumiere.

\section{Fuentes periodísticas y cinematográficas}

Brufman, Melina (octubre de 2012). "La danza de la vida". Revista El Tangauta (215), 19-26.

Guerriero, Leila (7 de mayo de 2017). “María Nieves Rego, tango de amor y odio". Diario El País. Link: https://elpais. com/elpais/2017/05/08/eps/1494194728_149419.html

Un Tango más (2015). Ficha Técnica del Documental: Dirección: Germán Kral. Producción ejecutiva: Wim Wenders. Guion: Germán Kral y Daniel Speck. Música: Luis Borda, Sexteto Mayor y Gerd Baumann. Reparto: María Nieves Rego, Juan Carlos Copes, Pablo Veron, Alejandra Gutty, Ayelén Álvarez Miño y Juan Malizia. 